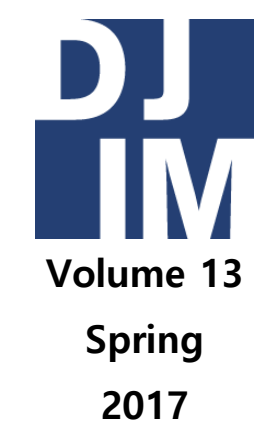

djim.management.dal.ca |

\title{
Understanding Conspiracy Online: Social Media and the Spread of Suspicious Thinking
}

Kim Mortimer

School of Information Management, Dalhousie University

\begin{abstract}
Even though the internet has dramatically changed the quantity and accessibility of information, there are large - and sometimes powerful — elements of society that are politically and emotionally invested in beliefs that are not supported by current evidence. These are generally referred to as "conspiracy theories." Although this may be a pejorative term, to date there is no suitable neutral term; the term conspiracy theory is used across multiple fields, ranging from computer science to cognitive science. In this paper I explore how conspiracy theories form, and how the internet has changed - or more frequently, not changed - the spread of conspiracy theories, in particular through social media networks such as Facebook or Twitter. Conspiracy theories spread much like scientific knowledge online, revealing that they are in some essences very similar constructs. The growth of user-specific filters and social exclusion are likely factors in the spread of these theories. Though some have argued to treat conspiracy theories as dangerous or harmful speech, such as in the case of vaccination refusal, I argue against limiting speech and instead suggest information literacy and a focus on analytical thinking as remedies. I also argue against further stigmatization of conspiracy theorists, as this will likely contribute to further radicalization.
\end{abstract}

\section{Understanding Conspiracy Online: Social Media and the Spread of Suspicious Thinking}

Despite global connectivity, satellite photographs, movies such as Apollo 13, and more, it is still possible to encounter people who believe in a flat Earth, for example, the rapper B.o.B (Ledbetter, 2016). How are people forming and holding these views despite the evidence to the contrary? The question is not purely academic. Conspiracy theories have had impacts on global health and environmental politics. For example, vaccine hesitancy is implicated in recent measles outbreaks (Frankel, 2015; Li, 2016). 
How are these theories spread online, especially through social media, when there is a wide abundance of information available that contradicts them?

The core of my paper is focused on understanding conspiracy theories, and how they continue to spread online today. Use of "conspiracy theory" can be problematic, as it generally confers a negative impression upon its subject and those who support it. For conciseness and compatibility with previous literature, I use it here and throughout this paper to refer to beliefs and general frameworks that typically reject the mainstream media, and the bulk of modern scientific literature, when it comes to a specific topic. My research focused on understanding how these beliefs and frameworks grow and spread online, in particular through social media.

The recent presidential election in the United States has brought several conspiracy theories back into public focus. The $45^{\text {th }}$ president was chastised by China for his skepticism on climate change (Wong, 2016), and met with Andrew Wakefield, whose nowretracted 1998 study on the mumpsmeasles-rubella vaccine claimed the vaccine could cause autism, spurring antivaccination activism (Kopplin, 2016). Despite these reports, I personally did not observe significant outreach to attempt to refute or correct these issues. Thus, I started my research in an attempt to synthesize existing knowledge and identify potential gaps. One issue I observed was a very limited number of papers analyzing the issue from the perspective of an information manager.

This paper is split into five sections, each containing a review of current research on conspiracy theories and related topics, followed by reflection and discussion. I start by exploring three conspiracy theories and how they impact modern society. I then explore what fuels belief in conspiracy theories, and how they spread. The next section focuses on how conspiracy theories spread online and what factors play a role in the spread. One recurring topic in information spread is the echo chamber: a group of individuals who share "similar levels of agreement about a subject and pass information among themselves via multiple pathways" (Fisher, Waggle, \& Jasny, 2015, p. 47). The presence or absence of echo chambers has a substantial impact on how information sharing occurs, and is given its own section. I conclude with a review of research on combatting or debunking these beliefs. Finally, through reflection and discussion I offer direction to future work in this area.

I must state that this paper will attempt to refrain from offering a value judgement of these theories. I instead ask that curious readers who consider themselves researchand information-literate browse the available research, investigate the various actors, and draw their own conclusions. Many of the articles I cite are clearly on one side or the other of these issues, and offer one place to start. I will also refrain from discussing the problem of fake or satirical news within this paper. Though these topics may be associated with the spread of conspiracies, they offer a different set of challenges and must be treated with a different ethical and moral approach.

\section{Contemporary Cons piracies}

In this section I provide an overview of three conspiracy theories which continue to influence our modern society. The continued belief in a flat Earth prompted my research into this topic, and forms the first part of this 
section. The anti-vaccination movement has influenced laws in the United States and is a source of major concern for groups such as the W orld Health Organization (Kata, 2012). Finally, climate change skepticism or denial is a recurring political issue, and has garnered support from prominent politicians (F isher et al., 2015). Although these are just a small sampling of conspiracy theories, they were chosen to reflect the largest sections of literature and research. They also happen to be among the topics that most influenced my interest in this work.

Given that it frames my introduction, a brief history of the flat Earth seems apt. The beginnings of modern flat Earth theories are traced back to Samuel Birley Rowbotham, who went by the pseudonym "Parallax." He began lecturing about a flat Earth in 1849, and attracted significant attention due to his skills in debating (Loxton, 2014, p. 69). Various leaders and spokespeople followed who would take up his views and were forced to adopt ever more radical perspectives in light of growing scientific knowledge and the space program. Despite this, historian Christine Garwood noted "[flat-Earth believers are so] little understood that their very existence is of some dispute" (Loxton, 2014 , p. 73), but it is clear from B.o.B that they still exist in some manner (Ledbetter, 2016).

Although vaccinations are now frequently administered to children in school and to members of the health care profession, some individuals have claimed that vaccines are dangerous, or otherwise simply not as effective as claimed. The modern antivaccination movement has several historical milestones, such as a 1982 documentary about the pertussis vaccine, Vaccine Roulette, which led to new laws in the US. Another is the now-retracted 1998 Wakefield paper, which claimed to link the mumpsmeasles-rubella vaccine with autism. Certain anti-vaccination "celebrities," such as Jenny McCarthy, use Twitter to share these views (Kata, 2012), while pro-vaccination websites exist to track associated deaths (Derek, 2015). The World Health Organization (WHO) continues to monitor and attempt to combat anti-vaccination beliefs due to potential health effects. J ane Parry quoted Dr. Sniadick of the WHO's Western Pacific Regional Office, who noted that following Japan's collective anxieties about the pertussis vaccine "there followed a resurgence of pertussis cases. A pertussis epidemic involving 13000 cases and 41 deaths occurred in 1979" (Parry, 2008, p. 426). The WHO formed an expert group on vaccine hesitancy in 2012, following a polio vaccine boycott in Nigeria (Fleck, 2014, p. 84). Recent resurgences in measles cases have been attributed to the vaccine refusal roughly half of the 1400 infected individuals from 2000-2015 were unvaccinated (Li, 2016).

There are some people who argue either climate change is not occurring, climate change is not caused by humans, or that the magnitude of climatic changes is not as large as claimed. Climate change skepticism and denial is moving from the political fringe to center stage. The U.S. chairman of the Senate Committee on Environment and Public Works as of 2015, Senator James Inohfe "wrote the book on climate science denial, literally. He titled it The Greatest Hoax..." (Fisher et al., p. 45). Perhaps the largest boon to climate skeptics was the 2009 "Climategate" email leak (Bricker, 2013). A hacker selectively released over 1000 emails between climate scientists. As media gained access to the files, the scientists were charged with conspiracy to 
tamper with the peer review process and inflate the effects of climate change. This resulted in a public opinion shift towards climate skepticism (Bricker, 2013). The recent election in the U.S. was soon followed by China attempting to dissuade climate change skepticism held by the president elect (Wong, 2016).

This is just a small sampling of the various theories and beliefs that are held today and transmitted via a mixture of conventional and unconventional means. Many of the studies within discuss different theories and use different evidence. Providing a comprehensive overview of all of them would be beyond the scope of this paper. However, these theories share several common elements, including their spread online.

\section{What Leads to Conspiracy Theories?}

Much of the early discourse on conspiracy theories originates from Hofstadter's 1964 essay "The Paranoid Style in American Politics." Hofstadter recognizes the pejorative nature of "paranoid" but offers several key insights. The first is what he describes as "The central preconception of the paranoid style - the existence of a vast, insidious, preternaturally effective international conspiratorial network designed to perpetrate acts of the most fiendish character" (Hofstadter, 1996, p. 14). He further elucidates that conspiracy theorists see "conspiracy as the motive force in historical events" (original emphasis, Hofstadter, 1996, p. 29). Finally, Hofstadter observed a certain obsession with gathering evidence (1996, p. 36). This evidence is then gathered and combined into a final "proof," reflective of scholarly arguments. The key difference between scholarly and conspiratorial works is "the curious leap in imagination that is always made at some crucial point" (Hofstadter, 1996, p. 37). Despite this gathering of evidence, Hofstadter notes that rather than expanding the knowledge of the researcher, it instead isolates the researcher from contradictory works (1996, p. 38).

Though Sunstein and Vermeule (2009) still approach the subject from a pejorative perspective - their paper ultimately recommends covertly infiltrating the ranks of those who spread conspiracy theories worthy of note is their discussion of conspiracy cascades and group polarization. A conspiracy cascade can be loosely defined as a series of events in which a single person's point of view about a significant event becomes the prevailing view of a group (Sunstein \& Vermeule, 2009). The conspiracy cascade begins with initial acceptance by a susceptible individual or group. This results in a growing repository of supporting information, which is the gathering of evidence previously discussed by Hofstadter (1996). External pressure grows due to the reputation of individuals who support the theory and the information they share, and more people begin to accept the theory. A sufficiently large group or a sufficiently reputable individual can be difficult to disagree with, thus gathering more members (Sunstein \& Vermeule, 2009, pp. 214-216). Emotions also play a role: "when rumors trigger intense feelings, they are far more likely to be circulated" (Sunstein \& Vermeule, 2009, p. 216). Finally, Sunstein and Vermeule argue that any group with some initial view inevitably adopts more extreme views with time (2009, p. 217).

Aupers (2012) generally attempts to prove conspiracy theorists are innocent of the various accusations levelled by Hofstadter (1996) or Sunstein and Vermeule (2009), and notes that conspiracy thinking has 
proliferated due to popular culture depictions of conspiracies, as well as real conspiracies such as Watergate. Aupers (2012) also argues that conspiracy theories arise from productive and healthy intellectual habits: "Conspiracy theorizing... embodies a radical form of reflexivity, criticism and skepticism" (p. 24). Aupers postulates that growing distrust of science likely reflects the increased publicity of scientific disputes in mainstream media, with specific reference to climate skepticism. The increased opacity of social systems is also drawn into consideration: "Conspiracy theories are cultural responses... strategies to rationalize anxieties by developing explicable accounts for seemingly inexplicable forces" (Aupers, 2012, p. 28). Overall Aupers (2012) argues that this growth in conspiracy thinking is simply a natural response to modernity.

Harambam and Aupers (2015) built off of Aupers' 2012 work in a survey that attempted to understand conspiracy theorists as "contesting the boundaries of science" ( $p$. 470). Participants in their study each held critical stances toward modern institutions, and an assumption that there was some form of external control over their collective lives (Aupers, 2012, pp. 470-471), which is vaguely reminiscent of the paranoia discussed by Hofstadter (1996). It is also worth noting that their belief is not passive: participants deconstructed standard views of the world and often constructed their own (Aupers, 2012, p. 471). There was also a general distrust in science, which they characterized as modern dogma influenced by capitalism. Conspiracy theorists "feel excluded, mocked, and stigmatized as "crazy" when they propose alternative ways of looking at the world" (Harambam \& Aupers, 2015, pp. 474-475).
Sometimes these alternate views stand in contradiction to one another. Wood, Douglas and Sutton experimentally observed that conspiracy theorists showed a positive correlation between the beliefs that Osama Bin Laden was already dead prior to the U.S. raid on his compound, and that Osama Bin Laden somehow escaped the raid alive. However, rather than reflecting the "curious leap" that Hofstadter observed or some other deficiency in reasoning, this can be explained by a higher level belief such as distrust in the official story about Bin Laden's death (Wood, Douglas, \& Sutton, 2012). Wood et al. (2012) thus suggest focusing on the overarching ideology shared between individual conspiracy theories rather than focusing on the differences between them.

Given the sense of exclusion noted by Harambum and Aupers, it is worthwhile to examine its role in conspiracy theories. Graeupner and Coman (2016) uncovered in experimental studies that a feeling of social exclusion results in higher endorsement of conspiracy theories. Work by van Prooijen (2016) also identified that prefacing conspiracy theories with messages of social belonging can increase the belief in conspiracy theories. As such, it would be possible to create the conspiracy cascade discussed by Sunstein and Vermeule (2009): social exclusion leads to individual conspiratorial thinking, social inclusion is achieved as a group begins to believe in the theory, and the inevitable extremism leads to continued exclusion (from moderate groups) and a sense of inclusion (within the ostracized group).

Human interaction clearly plays some role in how information is shared and conspiracy theories grow. Although I will not be modelling in this paper, one model of information sharing is the "echo chamber" 
model, which is defined by Fisher et al. (2015) as:

A group of three actors in which one individual is the source of information and transmits information to a second person both directly and indirectly through the third person... when three people hold similar levels of agreement about a subject and pass information among themselves via multiple pathways, we call it an echo chamber. (p. 47)

Echo chambers are a common topic in discussing communication online, especially when users can form informal groups centered on certain topics or based on affiliations. Few studies of online social media networks focus on the transitive triad, though this seems like an obvious direction for future modelling and visualization.

\section{How do Conspiracies Flourish Online?}

\section{The Sharing of Conspiracy}

Social media networks allow users to share relevant stories, and offer a window through which researchers can view this sharing. Del Vicario et al. (2016) observed that Facebook posts related to both science and conspiracy topics shared similar "lifetimes" - the time between the original post and the final time the post was shared. However, conspiracy rumors showed a positive correlation between lifetime and how many users were exposed to the rumor: longer lived conspiracies have more impact on social media, validating some of the ideas from Sunstein and Vermeule (2009) on cascades. This common lifetime was also reproduced by Bessi et al. (2015).
Bessi et al. (2015) took a closer look at how posts were commented, liked, and shared on Facebook. There were no significant differences in commenting patterns for conspiracy posts as compared to science posts, but conspiracy posts were more likely to be liked and shared by users (Bessi et al., 2015). Bessi et al. (2016) also studied videos on both Facebook and YouTube and noted science and conspiracy posts have similar user interaction profiles, which were measured by the numbers of likes and comments videos received. These results were replicated by Mocanu et al. (2015). However, Bessi et al. (2015; 2016) and Mocanu et al. (2015) did not study the emotions and sentiments associated with comments in their work, for example, whether particular types of posts were responded to positively or negatively. Sunstein and Vermeule (2009) argued intense emotions have a role in the spread of conspiracy, so understanding the emotions associated with this sharing seems relevant.

\section{Emotions and Sharing}

Zollo et al. (2015) used automatic sentiment analysis to attempt to understand the emotional state of users on Facebook who interacted with science and conspiracy pages. Results were divided into comments, posts, and users - users being the aggregate of their comments and posts and compared for the two communities. They were assigned a rating of positive, neutral or negative. One observation was that the majority of science comments, posts, and users were neutral compared to conspiracy comments, posts and users, which were much more negative. Conspiracy discussions were also more likely to become negative as the number of comments and likes increased (Zollo et al., 2015). This negative background may contribute to 
feelings of isolation amongst conspiracy theorists. However, no comparison was made to a baseline or control group, that is to say, a group without science or conspiracy discussions.

\section{Polarization and Homogeneity}

Bessi and Del Vicario have, across at least three papers (Bessi et al., 2015; Bessi et al., 2016; Del Vicario et al., 2016) used a single definition of polarization: a user's polarization towards conspiracy is the fraction of their interactions (posts, comments, and likes) that are only directed towards conspiracy news. Users who commented frequently on scientific posts were considered to hold a scientific polarization. Polarized users are those with a polarization greater than $95 \%$. Homogeneity is a measure of how similar two sharing users are in their personal polarization - the more similar two users are, the higher the homogeneity (Bessi et al., 2015; Bessi et al., 2016; Del Vicario et al., 2016).

One very interesting result is that most users on Facebook and YouTube are strongly polarized - more than $85 \%$ of users studied were either science-polarized or conspiracypolarized. Users on Facebook were more science-polarized, and on YouTube, users were more conspiracy-polarized. This also shows there are two distinct, isolated communities: one for science and one for conspiracy. Polarized users in the two groups displayed very similar commenting activity; thus, once strongly polarized, users behaved in similar ways despite the differences in content (Bessi et al., 2016). Likes and comments on Facebook were also very similar among polarized groups (Bessi et al., 2015).

Understanding Conspiracy Online
Another interesting difference was how science-polarized users commented on conspiracy news, and conspiracy-polarized users commented on scientific news. Conspiracy-polarized users commented roughly ten times less frequently on science news (comprising about $\sim 1 \%$ of total polarized comments) when compared to science polarized users commenting on conspiracy news (compromising about $10 \%$ of total polarized comments), even though there were only three times fewer scientific news articles. Conspiracy polarized users were also more likely to comment and like fake or satirical news (Bessi et al., 2015).

Despite this, Del Vicario et al. (2016) noted that conspiracy posts with larger cascades (that is, more success in spreading) generally had a lower homogeneity when compared to science posts. This seems to imply that more successful conspiracy theory posts attract a wider variety of users. Although there was this one particular exception, Del Vicario et al. (2016) state that "homogeneity is clearly the driver of information diffusion" (p. 556) for both science and conspiracy posts.

\section{The Filter B ubble Effect Online}

The strong polarization of users who share conspiracy news, combined with the high homogeneity, leads both Del Vicario et al. (2016) and Bessi et al. $(2015 ; 2016)$ to argue that their results are indicative of echo chambers. Echo chambers and filter bubbles are linked concepts. Filter bubbles generally refer to how a combination of personal preference and learning algorithms for displaying content, such as Facebook's news feed or Google's search personalization, results in users only being exposed to information that aligns with their pre-established beliefs. Thus, an echo 
chamber forms - sometimes without a user's knowledge (Flaxman, Goel, \& Rao, 2016; Messing \& W estwood, 2014). The term "filter bubble" originates from Pariser's 2011 book of the same name. Some further analysis of filter bubbles as related to information professionals is provided by Menchaca in his 2012 article, "The future is in doubt," which I discuss in more detail later.

Nyhan (2014) argues that echo chambers do not truly exist in user consumption patterns, noting surveys that show centrist ideologies form a core part of the information diet of respondents. He also hypothesizes that exposure to different ideologies results in a more diverse information diet (Nyhan, 2014). Unsurprisingly, Facebook employees (specifically Bakshy, E., Messing, S., \& Adamic, L., 2015) have argued their algorithms are not responsible for the filter bubble effect, but their own studies have shown some conflicting data: some contradictory news stories are removed or hidden from a polarized user's news feed. Its ranking of articles could also create an echo chamber in more subtle ways because the lower the algorithm ranks items, the less likely users are to click on them (Tufekci, 2015).

A variety of studies have attempted to better understand the precise impact of the effect of filter bubbles and echo chambers. J acobson, Myung, and Johnson (2016) observed that politically inclined users chose sources that agreed with their opinions much more often than those that disagreed with them. However, they also observed that there were a small number of "neutral" resources that were linked to frequently by both left and right leaning users. Unfortunately they did not perform semantic analysis of the links and discussion, leaving it unresolved as to whether these neutral resources were useful to decreasing polarization ( $\mathrm{J}$ acobson et al., 2016).

Messing and W estwood (2014) took a closer look at how social media services influence polarization. They observed that users who were shown social endorsements through non-personalized

Facebook 'recommendations' were more likely to select non-partisan or contrary sources. Thus, a popular source seems to encourage users to ignore any filtering practices they may have, increasing the diversity of opinions they are exposed to. They claim that this will "make it less likely for individuals to fall victim to falsehoods" (Messing \& Westwood, 2014, p. 1058).

Himelboim, McCreery, and Smith (2013) studied how users communicate and share links on Twitter within their networks. They focused on closed clusters of users and observed that clusters grow to reflect the prevailing political opinion; the users thus become more polarized, as hypothesized previously by Sunstein and Vermeule (2009). Polarized clusters were more likely to share ideologically similar links (Himelboim et al., 2013).

Flaxman, Goel, and Rao (2016) offered a comparison between social media networks and online search engines. They observed that both social media and online search generally exposed users to a wider arrange of opinions and opposing viewpoints when compared to news aggregators or directly navigating to a website (Flaxman et al., 2016). Intuitively, this makes some sense, as users who directly navigate to a site are explicitly ignoring other sources. Flaxman et al. (2016) also observed that less polarized users were more likely to consider ideologically challenging sources, reproducing previous effects. They finally 
measured ideological segregation as the expected difference in polarization between two users of a service, and argued higher segregation indicates a higher likelihood of filter bubbles, in the sense that users of the service are ideologically distinct subsets (Flaxman et al., 2016). This definition reads to me as if a source that attracts a very wide variety of users across the spectrum of polarization will measure a very high segregation, while a source with most users of a particular polarization - whether it is strongly polarized or not - will measure a very low segregation. Thus, a sciencefocused news source that attracts predominantly science-polarized users would seemingly have a low segregation, despite the implications of the term. They observed that search engines had larger measured segregations as compared to social media or directly navigating to a site (Flaxman et al., 2016).

These diverse studies demonstrate the double-edged sword of the internet. Users are able to form homogenous clusters, and thus form an echo chamber. Equally, the huge amount of sources online, and the ability to see what is popular among other people even people outside your network, offer the opportunity to expose users to heterogeneous sources of information. The main problem of online search and social media seems to be the drive to personalize results, rather than the networks themselves.

\section{Curbing Conspiracy - What Should be Done?}

If we are to challenge conspiracy thinking, what techniques and strategies ought to be used? In some situations, such as the antivaccination movement, it seems as if there is a moral imperative to intervene, so as to reduce harm. The spread of factually inaccurate information might also be considered harm. Martin (2015), in reflecting on the anti-vaccination movement in Australia, reported several attempts to curtail the speech of members of the movement. He argues that an intervention in this manner is not only an attempt at censorship, endangering free speech, and offers a series of arguments against any direct legal intervention (Martin, 2015). The WHO appears to agree: Larson, an anthropologist in the employ of the WHO argues that it is better to focus on the underlying individual issues pertaining to anti-vaccination sentiment (Fleck, 2014). If intervention is to be performed, it must be done in such a way that the rights of free speech and free association are not violated. An exception may be necessary in cases of direct incitement to violence or harm.

deHaven-Smith and Witt (2013) echo some of Martin's (2015) arguments, and criticize Sunstein and Vermeule's (2009) proposal for direct government infiltration of conspiracy theory groups (as included in Sunstein \& Vermeule, 2009). "[T]rying to suppress conspiracy theories simply exacerbates citizen disaffection while also undermining the traditional, healthy distrust Americans harbor towards unchecked political power" (deHaven-Smith \& Witt, 2013, p. 289). deHaven-Smith and Witt (2013) instead argue that the concerns of conspiracy theorists be listened to seriously and responded to honestly. They note that previous events that have grown into conspiracy theories, such as the September 11th, 2001 terrorist attacks, generally suffered from various investigative problems, such as loss of evidence or conflicts of interest. Their solution is to develop special procedures guaranteeing timely, comprehensive, objective and independent 
investigations into major events (deHavenSmith \& Witt, 2013). However, this proposal requires public or government funding to create this independent agency, and must in some way be done without compromising its independence. What about thinking on a smaller scale?

Directly challenging conspiracy theorists on their thinking or beliefs is one possible way for the general public to contribute. Einstein and G lick (2015) noted that users exposed to a conspiracy theory, and then asked whether they believed in it, reported they were less likely to believe in the conspiracy than the control group. They argue that, combined with their other survey results, asking questions acts as a subtle correction to a conspiracy theory (E instein \& G lick, 2015).

Swami, Voracek, Stieger, Tran, \& Furnham (2014) observed that by encouraging analytical thinking, belief in conspiracy theories dropped. They offer a variety of possible explanations for this, including the possibility that subjects primed to think analytically merely selected a more rational seeming solution rather than reporting on their true beliefs (Swami et al., 2014). By combining this result with Einstein and Glick's, it may be that users who are challenged directly on their conspiracy beliefs 'retreat' from them, perhaps to avoid being seen as "crazy", as noted previously in Harambam's (2015) and Auper's (2012) works. It is also possible that engaging in a critical discourse may encourage analytic thinking and broaden perceptions.

J ong and Dückers (2016) observed in their research a self-correcting effect on Twitter with regards to rumors. In some cases, users were cautious or curious about certain topics and began ad-hoc investigations. The authors suggest that at least some fraction of
Twitter users are constantly validating the information they are presented with, and thus participate in correcting the record ( $J$ ong \& Dückers, 2016). This almost seems like a ray of hope in contrast to the echo bubbles observed previously. One question is whether this "wisdom of crowds" could equally be exploited by those with less altruistic motives.

There are also technical solutions that could discourage conspiracy. Bode and Vraga (2015) noted that even when exposed to factually incorrect information, the presence of correcting information in a "related stories" section resulted in a decrease in factually incorrect user beliefs. These "related stories" were manipulated artificially on Facebook in their study, but an appropriate algorithm could reproduce the effect. One concern was that implementation may in fact expose users to incorrect information due to a relationship with an otherwise correct article. Another is that their "correction" was only successful with respect to genetically modified organism beliefs and not with respect to antivaccination beliefs (Bode $\&$ Vraga, 2015).

Bricker's 2013 study on Climategate offers five suggestions on how scientists and environmentalists ought to respond to climate skeptics. The first is to use lay terminology to better interact with the public and avoid charges of elitism. The second is to better elucidate issues of scientific uncertainty and climatic unpredictability by focusing on the known elements, including known minimum risk (Bricker, 2013, p. 234). The third is to ensure peer review processes are "transparent, accountable, and welcoming of healthy skepticism" (Bricker, 2013, p. 234). Scientists must also become debaters and public speakers, by developing rhetorical skills. Finally, scientists must be prepared to counter criticism actively rather 
than letting their research offer its own defense (Bricker, 2013, p. 235).

To effectively engage in debate, those wishing to challenge conspiracy ought to understand conventional strategies used to bolster the defense of conspiracy theories. Kata (2012) offers 4 tactics and 14 overused themes of the anti-vaccination community along with counter-evidence, which offers a strong background for those attempting to engage directly with the anti-vaccination community. One element of note include "skewing the science," in which antivaccination members ignore evidence against their cause, and ignore problems with evidence in support of their cause (Kata, 2012, pp. 3781-3782). Another element worth mentioning are underhanded tactics, such as typosquatting, which refers to buying up common typos of the URLS of their opponents and redirecting it to their own page (Kata, 2012, p. 3782).

\section{Reflection and Discussion}

I first turn back to the introduction, where I noted that "conspiracy theorist" is somewhat of a pejorative term. Husting and Orr (2007) offer a quite detailed argument against the term, arguing that it is "a reframing device that neutralizes questions about power and motive while turning the force of challenges back on their speakers" (Husting \& Orr, 2007, p. 146). Calling someone a conspiracy theorist is a way of de-legitimizing their position on an issue, and frequently requires an individual to come to their own defense (Husting \& Orr, 2007). As such, a more neutral term might be useful for discussing these topics, especially since feelings of social exclusion have been shown to increase conspiratorial thinking.
It also seems clear that Hofstadter's work on the "paranoid style," while extremely pejorative, still offers some insight into modern conspiracy theories. For example, the skewing of science reported by Kata (2012) in the anti-vaccination community is extremely reminiscent of the defensive research that Hofstadter described. Still, we must keep in mind that adherents to conspiracy theories are people, with all the corresponding rights and freedoms. There is also the possibility that new evidence might eventually come to light, therein validating their beliefs.

From the current state of research, the most obvious recommendation for online social media and search engines is to reduce the amount of personalization and filtering they offer. This ought to reduce the likelihood of users accidentally developing filter bubbles. However, reducing personalization also increases the likelihood of a user having a negative experience on one of these sites, which impacts their profitability. As such it will be difficult to convince Facebook, Google, and others to make this change; it does, however, offer a potential to bridge the gaps between polarized users, thus reducing the likelihood of conspiracy theories propagating absent alternate information.

The combination of social exclusion (e.g. physical isolation from sitting at a computer) with social inclusion (e.g. from participating in an online social network) is likely a contributing factor to the spread of conspiracy theories online. A more welcoming, open society might increase general social inclusion, and thus decrease the likelihood of individuals to lean towards more superstitious thinking, argued in more detail by Graeupner and Coman (2016). Information professionals such as librarians 
might play a role here, for example, through the development of community groups.

Based on the results of Swami et al. (2014) it seems that changes in thinking styles may also be useful to reduce the spread of conspiracy theories. I also argue, in line with the conclusions of Fisher et al. (2015), that information literacy is also relevant. Weibe (2015) carefully notes that this involves more than just knowledge of how to search:

Information literacy draws on a repertoire of critical inquiry skills. It involves knowing that there are different types of information, each with its own origin, purpose...; and habitually evaluating, questioning, and verifying what you find. Information literacy also involves understanding that there is no one perfect source to be coupled with each new question... (pp. 54-55)

Expanding on this concept, improved information literacy should be correlated with an increased knowledge of the limitations or biases of any particular source. For example, an information literate person might understand that someone selling self-help guides for surviving an impending apocalypse might have ulterior motives when implying that a huge asteroid will soon destroy the Earth, an example studied in more detail by Reyes and S mith (2014). An exact study of the tactics of a conspiracy community (as per Kata, 2012) is not strictly necessary, because certain arguments or approaches are less compelling to the information literate. They have already learned to challenge arguments, to evaluate sources, and explore the surrounding literature.
Information professionals might do more than just expand information literacy. Menchaca advocates for playing the role of "doubt engines" (2012, p. 406), exposing users to the wide array of research and data available, and sometimes curating it to locate the most relevant items. This, he argues, is a better implementation of the filter bubble, one in which research knowledge and information literacy, rather than emotional state or polarization, drives any filtering (Menchaca, 2012).

Taken as a whole, there seems to be two parallel pathways information professionals can take to slow or reverse the spread of conspiracy theories. The first is to encourage active intellectual discussion between believers in conspiracy theories and those who have labelled them as conspiracy theorists - often scientists, politicians, or other professionals. This ought to foster social inclusion amongst believers and expose them to a wider variety of opinions. Equally we can learn from them their underlying problems and how to better accommodate their concerns, for example through better disclosure of conflicts of interest or transparent peer review processes. This is also in agreement with principles of freedom of speech and association.

The second is to foster a culture of information literacy and analytical thinking. This should assist citizens in understanding the effects of filter bubbles online. It might also lead to people becoming more aware of the limitations or biases of their information sources, and ideally encourage them to search for a wider variety of sources. It may not be possible to fully break out of filter bubbles, nor to de-polarize individuals, but improved information literacy should be 
correlated with greater personal understanding of those elements.

\section{Conclusions}

Despite the vast array of information we can access online, it is not a panacea for suspicious thinking or conspiracy theories. Some aspects that fuel conspiracy theories such as social exclusion are factors both online and off. Social media networks and search engines offer personalization algorithms which can increase polarization, and, based on research, seem to result in echo chambers of like-minded users. The accessibility of conflicting views does not guarantee we will choose to access them, or let them impact us.

However, there is no fundamental difference between how social media spreads scientific theories and conspiracy theories. The key differences were in how users reacted to posts. Conspiracy-polarized users were less likely to interact with contradictory posts, and more likely to be negative in their reactions. These negative reactions may reinforce feelings of social exclusion and further drive polarization. Echo bubbles of similar opinions form online, even among those who are not conspiracy theorists. We should expect conspiracy theorists to have built their own echo bubbles, which reinforce their beliefs.

Even though there may seem to be a moral imperative to intervene against the spread of conspiracy theories, active interventions are likely to violate the freedom of speech of conspiracy theorists. A better approach is to actively engage with and debate conspiracy theorists, presenting them with conflicting evidence and fostering a greater sense of social belonging. We should also aim to better understand the underlying beliefs and assumptions that guide users towards conspiracy theories in the first place.

Beyond active debate, there are also several policy changes that could influence the spread of conspiracy. Politically, free speech should be upheld as a universal human right, and impartial investigative procedures ought to be followed for major events. Greater information literacy among the general public will also assist with disrupting the future spread of conspiracy theories. Online developers should also consider the impact their algorithms may have on encouraging the formation of echo chambers or filter bubbles among users. Scientists must prepare to engage with people of all skill levels and to identify the root causes of hesitancy or doubt for certain key issues, such as vaccination.

\section{References}

Aupers, S. (2012). 'Trust no one':

Modernization, paranoia and conspiracy culture. European J ournal of Communication, 27(1), 22-34. doi:10.1177/0267323111433566

Bakshy, E., Messing, S., \& Adamic, L. (2015). Exposure to ideologically diverse news and opinion on Facebook. Science. doi:10.1126/science.aaa1160

Bessi, A., Coletto, M., Davidescu, G. A., Scala, A., Caldarelli, G., \& Quattrociocchi, W. (2015). Science vs conspiracy: Collective narratives in the age of misinformation. PLOS ONE, 10(2), e0118093. doi: 10.1371/journal.pone.0118093

Bessi, A., Zollo, F., Del Vicario, M., Puliga, M., Scala, A., Caldarelli, G., . . . 
Quattrociocchi, W. (2016). Users polarization on Facebook and YouTube. PLOS ONE, 11(8), 1-24. doi:10.1371/journal.pone.0159641

Bode, L., \& Vraga, E. K. (2015). In related news, that was wrong: The correction of misinformation through related stories functionality in social media. J ournal of Communication, 65(4), 619-638.

doi:10.1111/jcom.12166

Bricker, B. J . (2013). Climategate: A case study in the intersection of facticity and conspiracy theory. Communication Studies, 64(2), 218239. doi:10.1080/10510974.2012.749294

deHaven-S mith, L., \& W itt, M. T. (2013). Conspiracy theory reconsidered: Responding to mass suspicions of political criminality in high office. Administration \& Society, 45(3), 267-295. doi:10.1177/0095399712459727

Del Vicario, M., Bessi, A., Zollo, F., Petroni, F., Scala, A., Caldarelli, G., ... Quattrociocchi, W. (2016). The spreading of misinformation online. Proceedings of the National Academy of Sciences of the United States of America, 113(3), 554-559. doi:10.1073/pnas.1517441113

Derek (2015). Anti-vaccine body count. Retrieved February 16, 2017 from http://www.jennymccarthybodycount. com/

Einstein, K. L., \& G lick, D. M. (2015). Do I think BLS data are BS? The consequences of conspiracy theories. Political Behavior, 37(3),
679-701. doi:10.1007/s11109-0149287-z

Fisher, D. R., Waggle, J ., \& J asny, L. (2015). Not a snowball's chance for science. Contexts, 14, 44-49. doi:10.1177/1536504215611896

Flaxman, S., Goel, S., \& Rao, J. M. (2016). Filter bubbles, echo chambers, and online news consumption. Public O pinion Quarterly, 80, 298-320. doi:10.1093/poq/nfw006

Fleck, F. (2014). Underlying issues are key to dispelling vaccine doubts. Bulletin of the World Health Organization, 92(2), 84-85. doi:10.2471/BLT.14.030214

Frankel, T. (2015). Forget 'anti-vaxxers.' The Disney measles outbreak could change the minds of an even more crucial group. The Washington Post. Retrieved from https://www.washingtonpost.com/ne ws/storyline/wp/2015/01/26/forgetanti-vaxxers-the-disney-measlesoutbreak-could-change-the-mindsof-an-even-more-crucialgroup/?utm term=.b7fc0dbea291

Graeupner, D., \& Coman, A. (2016). The dark side of meaning-making: How social exclusion leads to superstitious thinking. J ournal of Experimental Social Psychology, doi:10.1016/j.jesp.2016.10.003

Harambam, J ., \& Aupers, S. (2015). Contesting epistemic authority: Conspiracy theories on the boundaries of science. Public Understanding of Science, 24(4), 466-480. doi:10.1177/0963662514559891 
Himelboim, I., McC reery, S., \& S mith, M. (2013). Birds of a feather tweet together: Integrating network and content analyses to examine crossideology exposure on twitter. J ournal of Computer-Mediated Communication, 18(2), 40-60. doi:10.1111/jcc4.12001

Hofstadter, R. (1996). The paranoid style in American politics and other essays. Harvard University Press. R etrieved from http://blog.lix.cc/wpcontent/uploads/2011/05/HofstadterParanoid-Style-American-Politics.pdf

Husting, G ., \& Orr, M. (2007). Dangerous machinery: Conspiracy theorist as a transpersonal strategy of exclusion. Symbolic Interaction, 30(2), 127150. doi: 10.1525/si.2007.30.2.127

J acobson, S., Myung, E., \& J ohnson, S. L. (2016). Open media or echo chamber: The use of links in audience discussions on the Facebook pages of partisan news organizations. Information, Communication \& Society, 19(7), 875-891. doi:10.1080/1369118X.2015.106446 1

J ong, W., \& Dückers, M. L. A. (2016). Selfcorrecting mechanisms and echoeffects in social media: An analysis of the "gunman in the newsroom" crisis. Computers in Human Behavior, 59, 334-341. doi:10.1016/j.chb.2016.02.032

Kata, A. (2012). Anti-vaccine activists, web 2.0, and the postmodern paradigmAn overview of tactics and tropes used online by the anti-vaccination movement. Vaccine, 30(25), 3778-
3789. doi:

10.1016/j.vaccine.2011.11.112

Kopplin, Z. (2016). Trump met with prominent anti-vaccine activists during campaign. Science Magazine. doi: 10.1126/science.aal0407

Ledbetter, C. (2016). Neil deG rasse Tyson schools rapper B.o.B, who thinks the Earth is flat. The Huffington Post. Retrieved from http://www.huffingtonpost.com/entry/ bob-says-earth-is-flat-neil-degrassetyson us 56a65171e4b0d8cc109ab cb7

$L i$, J . (2016) Vaccine refusal linked to recent U.S. measles outbreak, study suggests. CBC News. Retrieved February 16, 2017 from http://www.cbc.ca/news/health/vacci nation-refusal-measles-outbreakstudy-1.3490506

Loxton, D. (2014). Flat Earth?! The convoluted story of a flatly mistaken idea. Skeptic, 19(4), 64A, 64B, 6573. Retrieved from http://search.proquest.com/docview/ $\underline{1643098333}$ ? accountid=10406

Martin, B. (2015). Censorship and free speech in scientific controversies. Science and Public Policy, 42(3), 377-386. doi:10.1093/scipol/scu061

Menchaca, F. (2012). The future is in doubt: Librarians, publishers, and networked learning in the 21st century. J ournal of Library Administration, 52(5), 396-410. doi:10.1080/01930826.2012.700804 
Messing, S., \& Westwood, S. J. (2014). Selective exposure in the age of social media: Endorsements trump partisan source affiliation when selecting news online. Communication Research, 41(8), 1042-1063. doi:10.1177/0093650212466406

Mocanu, D., Rossi, L., Zhang, Q., Karsai, M., \& Quattrociocchi, W. (2015). Collective attention in the age of (mis)information. Computers in Human Behavior, 51, Part B, 11981204. doi:10.1016/j.chb.2015.01.024

Nyhan, B. (2014). The myth of the ideological echo chamber. New York Times, 164(56666), 3-3. Retrieved from http://search.ebscohost.com/login.as $\mathrm{px}$ ? direct=true $\& \mathrm{db}=\mathrm{aph} \& \mathrm{AN}=990426$ $\underline{77 \& \text { site }=\text { ehost-live }}$

Parry, J . (2008). No vaccine for the scaremongers. Bulletin of the World Health Organization, 86(6), 425426.

Reyes, I., \& S mith, J . K. (2014). What they don't want you to know about planet X: Surviving 2012 and the aesthetics of conspiracy rhetoric. Communication Quarterly, 62(4), 399-415. doi:10.1080/01463373.2014.922483

Sunstein, C. R., \& Vermeule, A. (2009). Conspiracy theories: Causes and cures. J ournal of Political Philosophy, 17(2), 202-227. doi:10.1111/j.14679760.2008.00325.x

Swami, V., Voracek, M., Stieger, S., Tran, U. S., \& Furnham, A. (2014).
Analytic thinking reduces belief in conspiracy theories. Cognition, 133(3), 572-585. doi:http://dx.doi.org/10.1016/j.cogniti on.2014.08.006

Tufekci, Z. (2015). Facebook said its algorithms do help form echo chambers, and the tech press missed it. NPQ: New Perspectives Quarterly, 32(3), 9-12. doi:10.1111/npqu.11519

van Prooijen, J . (2016). Sometimes inclusion breeds suspicion: Selfuncertainty and belongingness predict belief in conspiracy theories. European J ournal of Social Psychology, 46(3), 267-279. doi:10.1002/ejsp.2157

Wiebe, T. J . (2015). The information literacy imperative in higher education. Liberal Education, 101/102(4/1), 52 57. Retrieved from http://search.proquest.com/docview/ $\underline{1777198877 \text { ? accountid }=10406}$

Wong, E. (2016). In sign of shifting roles, china gives U.S. a lecture on climate change. New York Times, pp. A16.

Wood, M. J ., Douglas, K. M., \& Sutton, R. M. (2012). Dead and alive: Beliefs in contradictory conspiracy theories. Social Psychological and Personality Science, 3(6), 767-773. doi:10.1177/1948550611434786

Zollo, F., Novak, P. K., Del Vicario, M., Bessi, A., Mozetič, I., Scala, A., ... Quattrociocchi, W. (2015). Emotional dynamics in the age of misinformation. PLOS ONE, 10(9), 1-22. doi:10.1371/journal.pone. 0138740 